\title{
Rapid Response to High-Dose, Pulsatile Erlotinib in Afatinib-Refractory Leptomeningeal Carcinomatosis from Adenocarcinoma of the Lung: A Case Report
}

\author{
Frank S. Fan
}

Section of Hematology and Oncology, Department of Medicine, Ministry of Health and Welfare Changhua Hospital, Changhua County, Taiwan

\section{Keywords}

Leptomeningeal carcinomatosis · Adenocarcinoma of the lung · Afatinib · Erlotinib

\begin{abstract}
Leptomeningeal carcinomatosis occurred in an old female patient who was on a standard dose of afatinib for the treatment of her non-small cell lung cancer harboring an epidermal growth factor receptor gene mutation sensitive to tyrosine kinase inhibitors when extracranial lesions were still under control. Shifting to high-dose, pulsatile erlotinib dramatically saved her from the devastating condition in a very short period of time. Inadequate afatinib concentration in cerebrospinal fluid is reasonably suspected, and there is a call for clinical trials testing high-dose afatinib in leptomeningeal carcinomatosis.
\end{abstract}

\section{Introduction}

Leptomeningeal carcinomatosis (LC) or neoplastic meningitis is a rare but disastrous complication of non-small cell lung cancer (NSCLC). Its prognosis is dismal despite a multi- 


\section{Case Reports in Oncology}

disciplinary approach, including whole-brain radiotherapy as well as systemic and intrathecal chemotherapy [1]. Although epidermal growth factor receptor tyrosine kinase inhibitors (EGFR-TKIs) demonstrate satisfactory therapeutic efficacy for metastatic NSCLC with activating EGFR gene mutations, adequate treatment protocols in LC remain unclarified. We report a successful experience of high-dose, pulsatile erlotinib administration for an NSCLC patient's neoplastic meningitis which developed while the primary lesion and extracranial metastasis were under stable control by standard-dose afatinib.

\section{Case Presentation}

A 68-year-old woman visited our clinic in February 2015 complaining of nonproductive cough exacerbated by talking for about 2 months. Poor appetite with a weight loss of $2-3 \mathrm{~kg}$ in 1 month was also noted. Hemoptysis, hoarseness, fever, chillness, chest pain, shortness of breath, acid regurgitation, and bone pain were denied. As a common housewife with hypertension on regular medical control, she did not smoke cigarettes, nor indulge in alcohol drinking.

Despite no significant findings on physical examination, her chest X-ray film revealed a mass shadow in the right middle lung field just adjacent to the hilum. A CT scan of the chest disclosed a right hilar tumor with obstructive pneumonitis in the right middle and upper lobes. Enlarged mediastinal lymph nodes, lymphangitis carcinomatosis of the whole right lung field, and a ground glass nodule, most likely a metastatic lesion, in the right lower lobe were also identified. A bone scan showed multiple metastases involving the skull, spine, ribs, sternum, pelvic bones, bilateral proximal femurs, and the medial aspect of the right knee.

Erythematous change and tumor infiltration were detected in the right bronchial trees on bronchoscope examination. A biopsy from the intermediate bronchiole of the right middle lobe led to a pathologic diagnosis of adenocarcinoma. A Leu858Arg (L858R) mutation of the EGFR gene was found by DNA study of the tumor.

The patient went to a medical center in northern Taiwan for a second opinion and there received daily oral treatment with $40 \mathrm{mg}$ afatinib since March 20, 2015. Her devastating disease status resolved quickly, and a stable condition was well maintained until April 27, 2016. At that time, she was admitted to the neurology ward of that hospital for impairment of memory, attention, calculation ability, as well as gait and movement disturbance. Frequent episodes of dizziness, vertigo, and falling were also notable. These symptoms had developed progressively in the previous 3 months according to her family. Evident paranoid delusion and depressed mood were detected during hospitalization. However, there was no headache, vomiting, cranial nerve palsy, decreased muscle power, seizure, visual or auditory hallucination.

A lumbar puncture was done. Cerebrospinal fluid (CSF) analysis showed a glucose level of $61 \mathrm{mg} / \mathrm{dl}$, a total protein level of $49 \mathrm{mg} / \mathrm{dl}$, and a white cell count of $8 / \mu$ l. All the white cells were lymphocytes. CSF cytospin cytology, however, disclosed atypical cells of undetermined significance as reported by the pathologist. Thus, a diagnosis of LC was made.

Because a positron emission tomography-CT scan performed 1 month prior to admission demonstrated only 3 small hot spots on the right pulmonary hilum, right middle lobe, and right iliac bone, afatinib treatment was kept on while the patient received whole-brain radiotherapy with 3,000 cGy in 10 fractions from May 23 to June 3, 2016. She was brought home after radiotherapy, with afatinib taken irregularly due to a progressive downhill consciousness level. 
By the time her family pushed her in a wheelchair into our outpatient clinic on June 28, 2016, she had already become unable to speak or eat, had no response to verbal order, and kept her eyes closed all the time. Acne, paronychia, and diarrhea were identified as probable adverse effects of afatinib at admission to the ward. Intravenous fluid supplementation and nasogastric tube feeding were established. A brain MRI showed diffuse abnormal leptomeningeal enhancement at bilateral cerebral and cerebellar hemispheres, compatible with LC (fig. 1a, b). On account of the uncooperative and irritable status, a lumbar puncture was not done.

After reviewing her previous medical record retrieved by her family, we decided to hold afatinib and prescribed mashed high-dose, pulsatile erlotinib 600 mg every 4 days through a nasogastric tube for rescue. In keeping with our expectation, the patient's consciousness level improved, as evidenced by opening her eyes to verbal stimulation after 2 doses of erlotinib. She could recognize her husband, smile, say simple sentences, and sit up on the bed with support after 4 doses. A second brain MRI revealed that the leptomeningeal lesions almost completely disappeared 17 days after the treatment had begun (fig. 1c, d). She was able to walk several steps to the toilet under supervision when she returned home and kept on erlotinib therapy. Her acne, paronychia, and diarrhea also resolved soon after afatinib was discontinued.

\section{Discussion}

A recent retrospective study of LC in NSCLC found that patients treated with EGFR-TKIs had a better overall survival than those without treatment [2]. This finding suggests that EGFR-TKIs can penetrate into CSF and eradicate sensitive NSCLC cells. A few case reports also provided evidence that a standard dose of either gefitinib (250 mg daily) or erlotinib (150 mg daily) could effectively improve neurologic symptoms in some NSCLC patients with activating EGFR gene mutations complicated with LC $[3,4]$. Interestingly, CSF cytologic conversion rates of standard-dose EGFR-TKIs in conjunction with intrathecal chemotherapy and whole-brain radiotherapy in LC patients were higher for erlotinib (64.3\%) than for gefitinib $(9.1 \%)$ in a retrospective clinical review [5]. This might be explained by the finding that the CSF concentration and the penetration rate of erlotinib were significantly better than those of gefitinib in NSCLC patients on EGFR-TKIs therapy [6].

Nevertheless, a large portion of LC patients remained unresponsive to standard-dose TKIs. To further improve the therapeutic effects of gefitinib and erlotinib on LC with activating EGFR gene mutations in NSCLC patients, high-dose protocols of both agents have been designed based on a later proved presumption that there was a good correlation between plasma and CSF concentrations of TKIs [7]. After the gefitinib dose was increased from 500 to $750 \mathrm{mg}$ and then to $1,000 \mathrm{mg}$ daily, a patient who had failed on the previous standard dose of gefitinib noted a great improvement of his headache and tremor along with both radiographic and cytologic responses [8]. Dramatic therapeutic effects of erlotinib in patients with LC resistant to the standard dose were also demonstrated when erlotinib was given at $600 \mathrm{mg}$ every 4 days [9], $450 \mathrm{mg}$ every 3 days [10], or 1,500 mg once a week [11, 12].

Despite the fact that a combined subset analysis of two randomized trials favors afatinib in providing better progression survival than standard systemic chemotherapy as the firstline treatment of brain metastasis in NSCLC with common EGFR gene mutations [13], the effect of afatinib in treating LC is still not well validated. Even though a good response and 
Fan: Rapid Response to High-Dose, Pulsatile Erlotinib in Afatinib-Refractory Leptomeningeal Carcinomatosis from Adenocarcinoma of the Lung: A Case Report

adequate CSF concentrations of standard-dose afatinib were shown in one NSCLC patient with EGFR-TKI-sensitive LC [14], our patient failed to benefit from afatinib for her LC when extracranial lesions were still under control by that drug.

High-dose, pulsatile erlotinib, on the other hand, helped her recover from the urgent condition. EGFR gene mutations resistant to afatinib can most likely be ruled out since erlotinib is still effective when given on an adjusted dosing schedule. It would be interesting to know whether high-dose afatinib will also provide satisfactory therapeutic efficacy. We did not adopt this policy because severe adverse effects of afatinib had already been observed in our patient under treatment with the standard dose. Before a clinical trial which clarifies the potency and toxicity of high-dose afatinib in NSCLC with common EGFR gene mutations is completed, shifting to high-dose erlotinib for patients complicated with LC is recommended based on our experience reported here, supposing that a resistant EGFR gene mutation, such as $\mathrm{T} 790 \mathrm{M}$, has not appeared.

\section{Statement of Ethics}

Written informed consent was obtained from the patient's husband for publication of this case report and the accompanying images. The copy of the written consent is available for review by the Editor-in-Chief of this journal.

\section{Disclosure Statement}

The author declares that there is no conflict of interest.

\section{References}

1 Morris PG, Reiner AS, Szenberg OR, Clarke JL, Panageas KS, Perez HR, Kris MG, Chan TA, DeAngelis LM, Omuro AM: Leptomeningeal metastasis from non-small cell lung cancer: survival and the impact of whole brain radiotherapy. J Thorac Oncol 2012;7:382-385.

2 Lee SJ, Lee JI, Nam DH, Ahn YC, Han JH, Sun JM, Ahn JS, Park K, Ahn MJ: Leptomeningeal carcinomatosis in non-small-cell lung cancer patients: impact on survival and correlated prognostic factors. J Thorac Oncol 2013;8:185-191.

3 Sakai M, Ishikawa S, Ito H, Ozawa Y, Yamamoto T, Onizuka M, Sakakibara Y: Carcinomatous meningitis from non-small-cell lung cancer responding to gefitinib. Int J Clin Oncol 2006;11:243-245.

4 Ohara G, Kagohashi K, Kurishima K, Kawaguchi M, Nakayama H, Satoh H: Recovery from carcinomatous meningitis by erlotinib. Onkologie 2011;34:394-395.

5 Lee E, Keam B, Kim DW, Kim TM, Lee SH, Chung DH, Heo DS: Erlotinib versus gefitinib for control of leptomeningeal carcinomatosis in non-small-cell lung cancer. J Thorac Oncol 2013;8:1069-1074.

-6 Togashi Y, Masago K, Masuda S, Mizuno T, Fukudo M, Ikemi Y, Sakamori Y, Nagai H, Kim YH, Katsura T, Mishima M: Cerebrospinal fluid concentration of gefitinib and erlotinib in patients with non-small cell lung cancer. Cancer Chemother Pharmacol 2012;70:399-405.

-7 Togashi Y, Masago K, Fukudo M, Tsuchido Y, Okuda C, Kim YH, Ikemi Y, Sakamori Y, Mio T, Katsura T, Mishima M: Efficacy of increased-dose erlotinib for central nervous system metastases in non-small cell lung cancer patients with epidermal growth factor receptor mutation. Cancer Chemother Pharmacol 2011;68:1089-1092.

-8 Jackman DM, Holmes AJ, Lindeman N, Wen PY, Kesari S, Borras AM, Bailey C, de Jong F, Jänne PA, Johnson BE: Response and resistance in a non-small-cell lung cancer patient with an epidermal growth factor receptor mutation and leptomeningeal metastases treated with high-dose gefitinib. J Clin Oncol 2006;24:4517-4520.

-9 Dhruva N, Socinski MA: Carcinomatous meningitis in non-small-cell lung cancer: response to high-dose erlotinib. J Clin Oncol 2009;27:e31-e32. 


\section{Case Reports in Oncology}

Fan: Rapid Response to High-Dose, Pulsatile Erlotinib in Afatinib-Refractory Leptomeningeal Carcinomatosis from Adenocarcinoma of the Lung: A Case Report

10 Kawamura T, Hata A, Takeshita J, Fujita S, Hayashi M, Tomii K, Katakami N: High-dose erlotinib for refractory leptomeningeal metastases after failure of standard-dose EGFR-TKIs. Cancer Chemother Pharmacol 2015;75:1261-1266.

11 Clarke JL, Pao W, Wu N, Miller VA, Lassman AB: High dose weekly erlotinib achieves therapeutic concentrations in CSF and is effective in leptomeningeal metastases from epidermal growth factor receptor mutant lung cancer. J Neurooncol 2010;99:283-286.

$\rightarrow 12$ Kuiper JL, Smit EF: High-dose, pulsatile erlotinib in two NSCLC patients with leptomeningeal metastases - one with a remarkable thoracic response as well. Lung Cancer 2013;80:102-105.

-13 Schuler M, Wu YL, Hirsh V, O’Byrne K, Yamamoto N, Mok T, Popat S, Sequist LV, Massey D, Zazulina V, Yang JC: First-line afatinib versus chemotherapy in patients with non-small cell lung cancer and common epidermal growth factor receptor gene mutations and brain metastases. J Thorac Oncol 2016;11:380-390.

14 Hoffknecht P, Tufman A, Wehler T, Pelzer T, Wiewrodt R, Schütz M, Serke M, Stöhlmacher-Williams J, Märten A, Maria Huber R, Dickgreber NJ; Afatinib Compassionate Use Consortium (ACUC): Efficacy of the irreversible ErbB family blocker afatinib in epidermal growth factor receptor (EGFR) tyrosine kinase inhibitor (TKI)-pretreated non-small-cell lung cancer patients with brain metastases or leptomeningeal disease. J Thorac Oncol 2015;10:156-163. 


\section{Case Reports in Oncology}

\begin{tabular}{l|l}
\hline Case Rep Oncol 2016;9:537-542 \\
\hline DOI: 10.1159/000449405 & $\begin{array}{l}\text { C 2016 The Author(s). Published by S. Karger AG, Basel } \\
\text { www.karger.com/cro }\end{array}$ \\
\hline
\end{tabular}

Fan: Rapid Response to High-Dose, Pulsatile Erlotinib in Afatinib-Refractory Leptomeningeal Carcinomatosis from Adenocarcinoma of the Lung: A Case Report

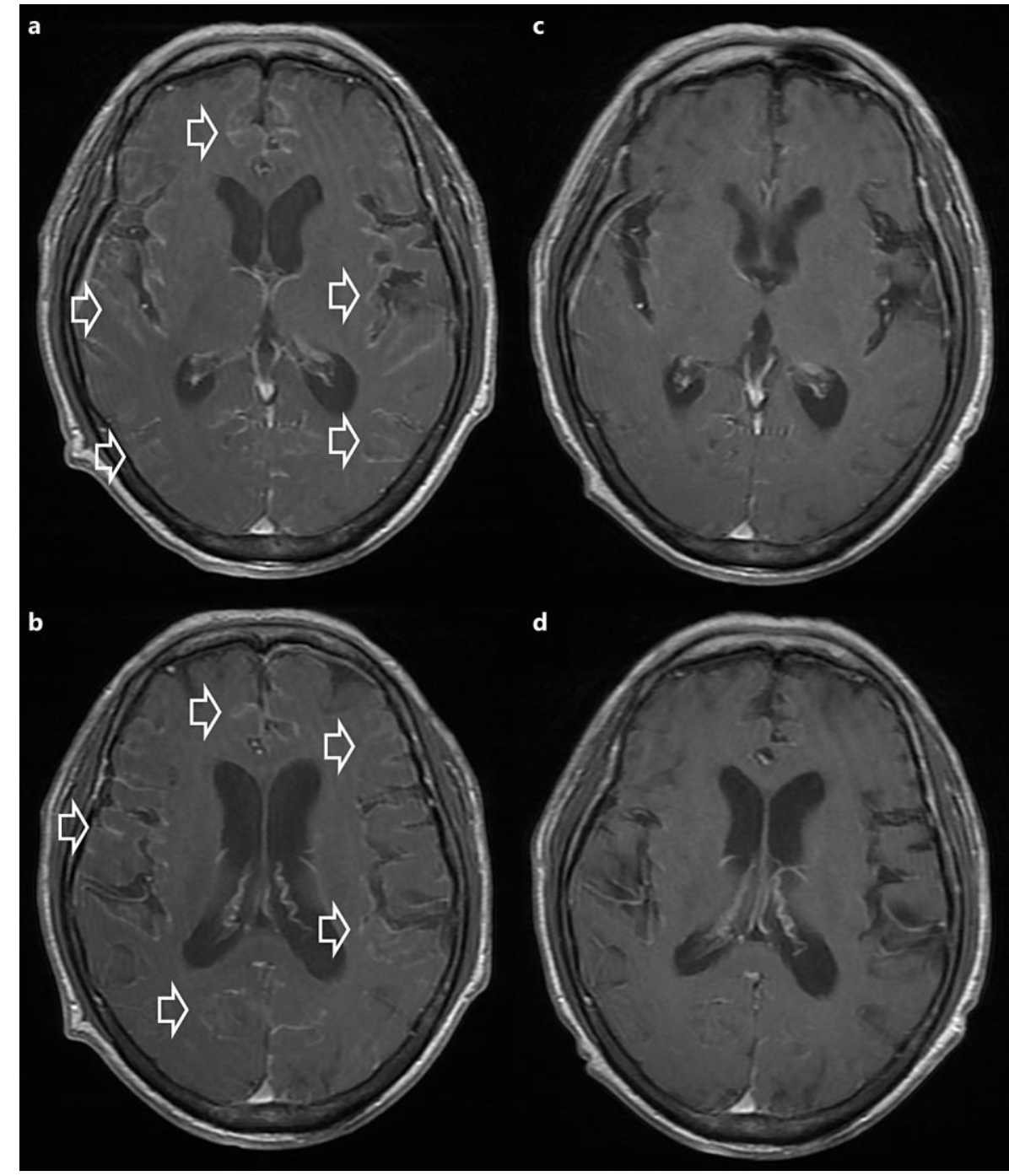

Fig. 1. Dramatic improvement of LC due to high-dose, pulsatile erlotinib therapy, as shown in the axial gadolinium-enhanced T1-weighted MRI of the brain. Arrows indicate leptomeningeal lesions. a, b July 4, 2016. c, d July 21, 2016. 